\title{
Educação Ambiental Patrimonial: um conceito em construção ${ }^{1}$
}

\author{
Educación Ambiental Patrimonial: un concepto en construcción \\ Patrimonial Education Environmental: a concept in construction
}

Célia Souza da Costa $^{2}$

\begin{abstract}
Resumo
A Educação Ambiental Patrimonial é mais conhecida como Educação Patrimonial. Trata-se de um conceito que está em evolução, especialmente no Brasil podendo ser utilizada nos âmbitos formais, informais e não formais educativos. Epistemologicamente é um termo em construção que necessita ser difundido. No Brasil, a maior parte das obras acerca do patrimônio cultural são fomentadas por publicações do Instituto de Patrimônio Histórico e Artístico Nacional (IPHAN) que adere ao termo Educação Patrimonial. O Brasil, assim como em outros países da América Latina possuem culturas e tradições específicas que necessitam ser cuidadas, protegidas, preservadas e conservadas por meio da Educação Ambiental Patrimonial (EAP), pois as intervenções e ações patrimoniais estão voltadas para o gerenciamento dos bens culturais materiais e imateriais, portanto do patrimônio cultural. O objetivo deste trabalho é discutir a importância da educação ambiental patrimonial enquanto conceito teórico. Para isso, utilizou-se como metodologia, a pesquisa qualitativa de cunho teórico bibliográfico por meio da leitura analítica e interpretativa. Dentre os autores que embasam a discussão acerca da educação ambiental patrimonial estão Marchette (2016), Paes (2013), Florêncio (2014/2015), Riffel (2017), Scifoni (2017) e Tolentino (2018). Já em relação à educação formal, informal e não formal destaca-se Maria da Glória Gohn (2006/2014). No viés da educação ambiental embasam a educação ambiental crítica Carvalho (2017) e Loureiro (2012); e Fiorillo (2015) sobre o meio ambiental cultural. Todos estes teóricos contribuem para a formação da concepção epistemológica da Educação Ambiental Patrimonial (EAP).
\end{abstract}

Palavras-Chave: Educação Ambiental Patrimonial; Educação formal, informal e não formal; Patrimônio Cultural; Epistemologia.

\section{Resumen}

La Educación Ambiental Patrimonial es más conocida como Educación Patrimonial. Se trata de un concepto que está en evolución, especialmente en Brasil, que puede ser utilizado en los ámbitos formales, informales y no formales educativos. Epistemológicamente es un término en construcción que necesita ser difundido. En Brasil, la mayor parte de las obras acerca del patrimonio cultural son fomentadas por publicaciones del Instituto de Patrimonio Histórico y Artístico Nacional (IPHAN) que se adhiere al término Educación Patrimonial. Brasil, así como en otros países de América Latina, poseen culturas y tradiciones específicas que necesitan ser cuidadas, protegidas, preservadas y conservadas por medio de la Educación Ambiental Patrimonial (EAP), pues las intervenciones y acciones patrimoniales están orientadas hacia el manejo de los bienes culturales materiales e inmateriales, por lo tanto del patrimonio cultural. El objetivo de este trabajo es discutir la importancia de la educación ambiental patrimonial como concepto teórico. Para ello, se utilizó como metodología, la investigación

\footnotetext{
${ }^{1}$ Artigo apresentado no Simpósio Temático ST 03- Repensar, Refletir, Interpretar e Reinterpretar a Memória, a identidade e o patrimônio cultural da América Colonial durante o II Seminário Latino-Americano de Estudos em Cultura - SEMLACult em Foz do Iguaçu/PR, Brasil, 2018. O presente trabalho foi realizado com o apoio da Coordenação de Aperfeiçoamento Pessoal de Nível Superior- Brasil (CAPES)-Código de Financiamento 001. Agradecimentos ao Instituto Federal do Amapá (IFAP).

${ }^{2}$ Doutoranda em Educação (PUC/PR); Pontifícia Universidade Católica do Paraná; Curitiba, Paraná, Brasil; celia.amapa@hotmail.com
} 
cualitativa de cuño teórico bibliográfico por medio de la lectura analítica e interpretativa. Entre los autores que fundamentan la discusión sobre la educación ambiental patrimonial están Marchette (2016), Paes (2013), Florencio (2014/2015), Riffel (2017), Scifoni (2017) y Tolentino (2018). En cuanto a la educación formal, informal y no formal se destaca María de la Gloria Gohn (2006/2014). En el sesgo de la educación ambiental basan la educación ambiental crítica Carvalho (2017) y Loureiro (2012); y Fiorillo (2015) sobre el medio ambiente cultural. Todos estos teóricos contribuyen a la formación de la concepción epistemológica de la Educación Ambiental Patrimonial (EAP).

Palabras claves: Educación Ambiental Patrimonial; Educación formal, informal y no formal; Patrimonio cultural; Epistemología.

\begin{abstract}
The Patrimonial Environmental Education is better known as Patrimonial Education. It is a concept that is evolving, especially in Brazil and can be used in formal, informal and non-formal educational settings. Epistemologically it is a term under construction that needs to be diffused. In Brazil, most works on cultural heritage are promoted by publications of the National Historical and Artistic Heritage Institute (IPHAN), which adheres to the term Patrimonial Education. Brazil, as in other Latin American countries, has specific cultures and traditions that need to be cared for, protected, preserved and preserved through Environmental Heritage Education (EAP), since the interventions and patrimonial actions are directed to the management of cultural assets material and immaterial, and thus of cultural heritage. The objective of this work is to discuss the importance of patrimonial environmental education as a theoretical concept. For this, the qualitative research of theoretical bibliographical by means of the analytical and interpretative reading was used as methodology. Among the authors who support the discussion about heritage environmental education are Marchette (2016), Paes (2013), Florêncio (2014/2015), Riffel (2017), Scifoni (2017) and Tolentino (2018). Regarding formal, informal and non-formal education, Maria da Glória Gohn (2006/2014) stands out. The environmental education bias is based on critical environmental education Carvalho (2017) and Loureiro (2012); and Fiorillo (2015) on the cultural environment. All these theorists contribute to the formation of the epistemological conception of Environmental Heritage Education (EAP).
\end{abstract}

Keywords: Environmental Environmental Education; Formal, informal and non-formal education; Cultural heritage; Epistemology.

\title{
1. Introdução
}

Com o advento da política de educação ambiental, o tema educação patrimonial se difunde, principalmente por meio das ações e intervenções promovidas pelo Instituto do Patrimônio Histórico Nacional (IPHAN), poder público e demais organizações da sociedade civil. Pois, a educação patrimonial é fundamental para o cuidado, preservação e conservação do patrimônio cultural material e imaterial.

Segundo Paes (2013, p.30) existe uma "tentativa de estabelecer um marco zero para a 'educação patrimonial', fixando uma data de nascimento (1983)", na cidade de Petrópolis, no Museu Imperial. No Brasil, as publicações sobre educação patrimonial foram impulsionadas pelo IPHAN com mais intensidade a partir dos primeiros anos do século XXI. Tanto que dezenas de livros, manuais, revistas, cartilhas e outros materiais estão disponíveis no site do IPHAN. Porém, o ponto de partida teórico acerca da educação patrimonial se deu através de uma produção de autoria de Maria de Lourdes Parreira, Evelina Grunberg e Adriane Queiroz Monteiro intitulada Guia Básico da Educação Patrimonial publicada em 1999. 
Vale ressaltar que questões voltadas para o patrimônio cultural são discutidas desde 1937 quando foi fundado o IPHAN, já que essa instituição surgiu com o propósito de promover e realizar “[...] ações educativas como estratégia de proteção e preservação do patrimônio sob sua responsabilidade, instaurando um campo de discussões teóricas, e conceituais e metodologias de atuação que se encontram na base das atuais políticas públicas" (FLORÊNCIO et al., 2014, p.5).

Nesta perspectiva, o objetivo deste trabalho é discutir sobre a importância da educação ambiental patrimonial enquanto conceito teórico. Enquanto alguns teóricos tratam o conceito somente como educação patrimonial (EP), outros aderem ao conceito Educação Patrimonial Ambiental (EPA), pessoalmente devido minha formação em Direito Ambiental e Políticas Públicas $^{3}$ e toda trajetória de estudos prefiro utilizar o termo Educação Ambiental Patrimonial (EAP), questão epistemológica que será fundamentada ao longo desta produção.

\section{Metodologia qualitativa: instrumento que possibilita a discussão teórica}

Segundo Creswel (2014, p. 49), "a pesquisa qualitativa começa com pressupostos e o uso de estruturas interpretativas/teóricas que informam o estudo dos problemas da pesquisa, abordando os significados que os indivíduos [...] atribuem a um problema social humano". A respeito da pesquisa qualitativa, Alami, Desjeux e Garabuau-Moussaoui (2010, p.28, 29) explicam que "não basta propor uma resposta metodológica que resolva o problema ou propor uma prática de estudos tecnicamente aceitável; é necessário que um efeito de situação permita uma apropriação social [...] de forma a permitir, em um segundo momento, sua difusão".

No viés da pesquisa qualitativa, Gray $(2012$, p.84) defende a importância da pesquisa de cunho bibliográfico, já que ela produz "a capacidade de outros pesquisadores de aprofundar os estudos que vieram antes", para esse movimento se da o nome de 'geratividade' e isso "ajuda a desenvolver a integridade e a sofisticação em pesquisa". Porém, Gray (2010, p.84) admite que é mais complicado ocorrer a geratividade "em campos que ainda não estejam bem estabelecidos ou onde o conhecimento for fragmentado ou contestado".

Como este estudo está baseado em pesquisas anteriores sobre o tema Educação Patrimonial, se optou em utilizar a leitura analítica do material, que de acordo com Gil (2010, p.59,60) “[...] a postura do pesquisador, nesta fase, deverá ser a de analisá-los como se fossem

\footnotetext{
${ }^{3}$ Mestrado em Direito Ambiental e Políticas Públicas pela Universidade Federal do Amapá, na qual defendeu a dissertação intitulada Patrimônio Cultural do Amapá: o caso das Louceiras do Maruanum em observância ao Princípio da Equidade Intergeracional.
} 
definitivos. A finalidade da leitura analítica é a de ordenar e sumariar as informações [...] de forma que estas possibilitem a obtenção de respostas ao problema da pesquisa".

No que concerne à leitura interpretativa, Gil (2010, p.60) diz que “[...] tem por objetivo relacionar o que o autor afirma com o problema para qual se propõe uma solução. Na leitura interpretativa, procura-se conferir significado mais amplo aos resultados obtidos [...]”.

\section{O que é educação patrimonial? Qual a convergência com a educação formal, não-} formal e informal?

Na ótica de Horta, Grunberg e Monteiro (1999, p.4), a educação patrimonial é “um processo permanente e sistemático de trabalho educacional centrado no Patrimônio Cultural como fonte primária de conhecimento e enriquecimento individual e coletivo". Portanto, as ações e intervenções voltadas à educação patrimonial devem propiciar "o contato direto com as evidências e manifestações da cultura, em todos os seus múltiplos aspectos, sentidos e significados".

Nesta linha de pensamento, Horta, Grunberg e Monteiro (1999, p.4) informam que a educação patrimonial busca sensibilizar as pessoas através “[...] de conhecimento, apropriação e valorização de sua herança cultural, capacitando-os para um melhor usufruto destes bens, e propiciando a geração e a produção de novos conhecimentos [...]".

Na concepção de Grunberg (2007, p.5) a Educação Patrimonial é "um o processo permanente e sistemático de trabalho educativo, que tem como ponto de partida e centro o Patrimônio Cultural com todas as suas manifestações”. Para as práticas de educação patrimonial, Grunberg (2007, p.6) menciona que a metodologia da educação patrimonial está dividida em quatro partes: observação (percepção sensorial, exploratória); registro (desenhos, descrições, mapas, fotos); exploração (discussões, questionamentos, análise do bem cultural) e a apropriação (recriação do bem, releitura).

Segundo Grunberg (2007, p.6) "a aplicação desta metodologia desenvolve atividades que levam os participantes à reflexão, descoberta e atitude favorável a respeito da importância e valorização do nosso Patrimônio Cultural”. Então, a educação ambiental patrimonial para alcançar estes objetivos tem como traço a processualidade, é uma atividade processual que envolve tempo e continuidade para surtir efeitos educativos. É necessário planejamento, reflexão e avaliação permanente para conduzir as atividades educativas.

Florêncio et al. (2014, p.19) afirmam que para o Centro de Educação Patrimonial (CEDUC/IPHAN) a Educação Patrimonial é formada por "todos os processos educativos formais e não-formais que têm como foco o Patrimônio Cultural, apropriado socialmente 
como recurso para a compreensão sócio-histórica das referências culturais em todas as suas manifestações". Por si só, o objetivo da educação patrimonial é gerar reconhecimento, cuidado,valorização e preservação do patrimônio cultural.

Como uma dinâmica cíclica, Florêncio et al. (2014, p. 19) mencionam que segundo o CEDUC/IPHAN, a educação patrimonial é constituída por "processos educativos devem primar pela construção coletiva e democrática do conhecimento, [...] pela participação efetiva das comunidades detentoras e produtoras das referências culturais [...]".

A esse respeito, Riffel (2017, p.50) diz que o papel da educação patrimonial é "promover ações educativas que tenham como premissa a identificação de expressões culturais locais e territoriais e precisa, sobremaneira, compreender os espaços públicos e comunitários como espaços formativos". O objetivo da educação patrimonial é antes de tudo é "construir mecanismos que agenciem a valorização dos bens culturais junto às comunidades, essas práticas potencializam o estabelecimento e fortalecimento de vínculos das comunidades com seus patrimônios".

Certamente, a educação patrimonial pode praticada nos mais diversos ambientes sociais, ela não é uma ação específica e unicamente de responsabilidade do âmbito escolar, ela pode circular na educação formal, informal e não- formal. Logo, há uma convergência entre e educação patrimonial e essas três formas de educação.

Para auxiliar na diferenciação entre estes tipos de educação, Gohn (2006a, p.2) classifica a educação formal como "aquela desenvolvida nas escolas, com conteúdos previamente demarcados", ou seja, é a educação oferecida na escola. Assim, Gohn explica que "a educação formal pressupõe ambientes normatizados, com regras e padrões comportamentais definido previamente". Os objetivos da educação formal são "relativos ao ensino e aprendizagem de conteúdos historicamente sistematizados, normalizados por leis, [...] formar o indivíduo como um cidadão ativo, desenvolver habilidades e competências [...]”.

Já a educação informal, segundo Gohn (2006b, p.28) é “aquela que os indivíduos aprendem durante seu processo de socialização- na família, bairro, clube, amigos etc., carregada de valores e culturas próprias, de pertencimento e sentimentos herdados". Neste liame, a educação informal na visão de Gohn (2006a, p.2) "socializa os indivíduos, desenvolve hábitos, atitudes, comportamentos, modos de pensar e de se expressar no uso da linguagem, segundo valores e crenças de grupos [...] que pertence por herança [...]”. Deste modo, “a educação informal não é organizada, os conhecimentos não são sistematizados e são repassados a partir das práticas e experiência anteriores, usualmente é o passado orientando o presente. Ela atua no campo das emoções e sentimentos". 
No que concerne à educação não-formal, Gohn (2006a, p.2) diz que é "aquela que se aprende 'no mundo da vida', via os processos de compartilhamento de experiências, principalmente em espaços e ações coletivas cotidianas". O intuito desta forma de educação "é abrir janelas de conhecimento sobre o mundo que circunda os indivíduos e suas relações sociais. Seus objetivos não são dados a priori, eles se constroem no processo interativo, gerando um processo educativo". Ademais, a educação não-formal apesar de não ter objetivos específicos, ela tem "uma intencionalidade na ação, no ato de participar, de aprender e de transmitir ou trocar saberes [...] situa-se no campo da Pedagogia Social- aquela que trabalha com coletivos e se preocupa com os processos de construção de aprendizagens e saberes [...]”.

Sendo assim, tanto a educação formal, informal e não-formal com todas as suas características e intenções formativas específicas podem ser meios para a aplicabilidade da educação ambiental patrimonial. Deste modo, cada ação conforme o tipo de educação que se pretende trabalhar surtirá efeitos distintos, mas que culminará para a mesma meta que é a proteção, o cuidado, a preservação e a perpetuação dos bens culturais e patrimônios existentes em uma comunidade.

\section{4 . Por que utilizar o termo Educação Ambiental Patrimonial?}

A educação patrimonial atribuída neste trabalho como Educação Ambiental Patrimonial (EAP) começou a ganhar novos contornos após a conclusão da minha dissertação e se tornou mais presente na construção do projeto de pesquisa para o doutorado. Com os estudos e pesquisas voltadas para o direito ambiental, um dos assuntos estudados foi a educação ambiental que pode ser vislumbrada de múltiplas formas, mas nesta produção se optou pelo viés jurídico e educacional por meio da educação ambiental.

Pois, a legislação brasileira, especialmente a Constituição Federal de 1998 (art. 225, art.182, art. 216, art. 200, dentre outros) contempla o meio ambiente em cinco dimensões: natural, artificial, cultural, do trabalho e mais recentemente do patrimônio genético (FIORILLO, 2015). Sobre isso, Loureiro (2012, p. 87) destaca que é a partir dos anos oitenta que a educação ambiental ganha visibilidade devido a "sua inclusão na Constituição Federal de $1988 "$.

No artigo 216 da Constituição Federal de 1988, fazem parte do rol de patrimônio cultural brasileiro "[...] os bens de natureza material ou imaterial, tomados individualmente ou em conjunto, portadores de referência à identidade, à ação, à memória dos diferentes grupos formadores da sociedade brasileira" (BRASIL, 1988). 
Como assinala Fiorillo (2015, p.430) “a Constituição não faz restrição a qualquer tipo de bem, de modo que podem ser materiais ou imateriais, singulares ou coletivos, móveis ou imóveis". A todos esses bens culturais é garantida a proteção, sejam elas de origem natural ou de intervenção humana. Porém, para que "um bem seja considerado como patrimônio histórico é necessária a existência de nexo vinculante com a identidade, a ação e a memória dos diferentes grupos formadores da sociedade brasileira'.

Então, o meio ambiente cultural, assim como as outras dimensões ambientais precisam de intervenção educacional para que haja o cuidado, a conservação e preservação dos bens culturais tutelados. Daí surge, a educação ambiental que é constituída por "processos por meio dos quais o indivíduo e a coletividade constroem valores sociais, conhecimentos, habilidades, atitudes e competências voltadas para a conservação do meio ambiente, bem de uso comum do povo" [...] (BRASIL, 1999).

A educação ambiental também pode ser conceituada como "uma perspectiva que se inscreve e se dinamiza na própria educação, formada nas relações estabelecidas entre as múltiplas tendências pedagógicas [...], que têm no 'ambiente' e na 'natureza' categorias centrais e identitárias" (LOUREIRO, 2004, p.66).

Neste enfoque, vale ressaltar que para Loureiro (2012, p.86) "a educação ambiental não é a busca da linguagem universal e única, mas o desafio constante de entender a relação entre o particular e o universal". Isso significa que a educação ambiental emancipatória e crítica tem como característica ultrapassar certos conceitos hierarquizados do que é ciência, com o olhar voltado a valorização dos conhecimentos populares, o que possibilitam "rupturas com o modelo contemporâneo de sociedade".

Sendo assim, EAP é uma vertente da educação ambiental, voltada para o cuidado, conservação e preservação específica do meio ambiente cultural que permanece interligado com os outros meios ambientes (natural artificial, do trabalho, genético), mas que tem um tratamento diferenciado voltado para os bens culturais materiais e imateriais que se constituem enquanto patrimônio cultural. Enquanto conceito teórico epistemológico, a educação ambiental patrimonial como termo adere a educação ambiental e aos preceitos jurídicos de patrimônio cultural, tornando-se uma vertente da educação ambiental.

\section{Conclusões}

A intenção deste trabalho se concentrou em compartilhar um conceito em construção que é a Educação Ambiental Patrimonial (EAP). Como não há um consenso de termos quando se trata da Educação Patrimonial, defendo o termo EAP, que engloba o patrimônio 
cultural como parte do meio ambiente e se apresenta de forma múltipla e podendo ser utilizada de acordo com a realidade que é observada.

A maior vantagem em utilizar o conceito EAP é reconhecer que o patrimônio cultural está associado com o meio ambiente, portanto também é objeto da educação ambiental que está embasada nas legislações brasileiras. Quanto as limitações, o termo EAP ainda é pouco utilizado e se encontra em processo embrionário e gestacional. Por sua vez, a EAP não deve ser confundido com a Educação Patrimonial Ambiental (EPA), termo estudado pelo Grupo de Pesquisas em Estudos em Educação Patrimonial Ambiental (GEPAM) que está ancorada na educação ambiental, representações sociais, na fundamentação de Paulo Freire e na educação formal e não-formal (BARROS, 2015; BARROS, MOLINA e SILVA, 2011).

Apesar da EPA ser distinta da EAP, a EAP enquanto conceito converge com a EPA quando se trata da educação ambiental, das representações sociais e da epistemologia Freiriana, e se diferencia porque tem como parâmetro a legislação ambiental, de cunho jurídico e a educação em três níveis: formal, informal e não-formal. Sendo assim, a EAP como um conceito é um campo convidativo para que mais pesquisadores e investigadores busquem contribuir para o fortalecimento conceitual, especialmente com a aderência do termo em suas escritas acadêmicas.

\section{Referências}

ALAMI, S.; DESJEUX, D.; GARABUAU-MOUSSAOUI, I. Os métodos qualitativos. Tradução Luis Alberto S. Peretti. Petrópolis: Vozes, 2010. 147 p.

BRASIL. Política Nacional de Educação Ambiental. Lei $\mathrm{n}^{\circ}$ 9.795/1999. Disponível em:http://www2.mma.gov.br/port/conama/legiabre.cfm?codlegi=321.Acesso em: 16 julho 2018.

$\begin{array}{llccr}\text { Constituição } & \text { Federal } & \text { de } & \text { 1988. } & \text { Disponível } \\ \text { em:http://www.planalto.gov.br/ccivil__03/Constituicao/Constituicao.htm.Acesso } & \text { em: } & 15 \\ \text { dezembro 2018. } & & \end{array}$

BARROS, J.V; MOLINA, M.D.; SILVA, M.F.V. Evoluindo com a construção de um novo conceito-educação patrimonial ambiental- a partir das reflexões da educação patrimonial e ambiental com vistas a ampliação do campo metodológico desse contexto. Fórum Ambiental da Alta Paulista, [S.1.], v. 07, n.06, p. 982-993, out. 2011. ISSN 1980-0827. Disponível em:http://www.amigosdanatureza.org.br/publicacoes/index.php/forum_ambiental/article/vie w/173. Acesso em: $15 \mathrm{dez} .2018$.

BARROS, J. Construção teórico metodológica da educação patrimonial ambiental a partir da meta análise de dissertações produzidas pelo grupo GEPAM. In: CONGRESSO NACIONAL DE EDUCAÇÃ̃O, 12., 2015, Curitiba. Anais do I Congresso Internacional de Pedagogia Social. Curitiba, 2015. 
CRESWELL, J. W. Investigação qualitativa e projeto de pesquisa: escolhendo entre cinco abordagens. Tradução Sandra Mallmann da Rosa. Porto Alegre: Penso, 2014. 341 p.

FLORÊNCIO, S.R.R. et al. Educação Patrimonial: histórico, conceitos e processos. Brasília: IPHAN,2014. 65 p.

FIORILLO, C.A.P. Curso de direito ambiental brasileiro. 16. Ed. São Paulo, Saraiva, $2015.1040 \mathrm{p}$.

GIL, A.C. Como elaborar projetos de pesquisa. São Paulo: Atlas,2010. 184 p.

GOHN, M.G. Educação não-formal na pedagogia social. In: CONGRESSO INTERNACIONAL DE PEDAGOGIA SOCIAL, 1., 2006, São Paulo. Anais do I Congresso Internacional de Pedagogia Social. São Paulo, 2006a.

Educação não-formal, participação da sociedade civil e estruturas colegiadas na escola. Revista Ensaio: Avaliação e Políticas Públicas em Educação, [S.1.], v. 4, n. 07, p.2738, jan./mar.2006b. ISSN 1809-4465. Disponível em:http://revistas.cesgranrio.org.br/index.php/ensaio/article/view/694. Acesso em: $15 \mathrm{dez}$. 2018.

GRAY, D.E. Pesquisa no mundo real. Tradução Roberto Cataldo Costa. Porto Alegre: Penso,2012. 486 p.

GRUNBERG, E. Manual de atividades práticas de educação patrimonial. Brasília: IPHAN,2007. 24 p.

HORTA, M.L.P.; GRUNBERG, E.; MONTEIRO, A.Q. Guia Básico da Educação Patrimonial. Brasília: Museu Imperial/IPHAN/MINC,1999. 69 p.

LOUREIRO, C. F. B. Educação ambiental transformadora. In: LAYRARGUES, P. P. (Org.) Identidades da Educação Ambiental Brasileira. Brasília: Ministério do Meio Ambiente, 2004.p.65-84.

. Trajetórias e fundamentos da educação ambiental. $4^{\mathrm{a}}$ ed. São Paulo: Cortez, 2012. $147 \mathrm{p}$.

PAES, D.L.N. Sob os signos das boiadas: da pesquisa à educação patrimonial In: TOLENTINO, A.B. (Org.). Educação Patrimonial: educação, memórias e identidades. João Pessoa: IPHAN, 2013. p. 32-41.

RIFFEL, R. Educação Patrimonial e os processos educativos: referências culturais como espaços de ensino-aprendizagem na educação básica. Revista História UNICAPUniversidade Católica de Pernambuco, [S.1.], v. 4, n. 07, p. 47-59, jan./jun 2014. ISSN 2359-2370.

Disponível em:http://www.unicap.br/ojs/index.php/historia/article/view/968/897.Acesso em: 15 dez. 2018. 